\title{
How are Kawaii (Cute) Fictional Characters Used in Japanese Advertising
}

\author{
Oana-Maria BîRLEA, PhD \\ Department of Japanese Language and Literature \\ Faculty of Letters \\ Babes-Bolyai University, Cluj-Napoca, Romania \\ E-mail: oana.birlea@lett.ubbcluj.ro
}

\begin{abstract}
This article aims to explain the use and role of cute, adorable characters in fapanese advertising. Kawaii culture or the "culture of cute" has become known worldwide mainly because of Hello Kitty, the cat which led the "pink globalization", as Yano (2013) states. In this paper we have attempted to reveal the symbolism of these apparent meaningless cute signs and characters. Starting from Hofstede's theory of cultural dimensions (2001, 2003, 2010), which shows how a society's culture influences the values of its members, we intended to show how are these kawaii characters used in Japanese advertising and how they fit cultural specifics. Used either in non-commercial, educational or commercial advertising, cute personae can make the target audience feel more comfortable, secure and cooperating (Murakami, 2005). In this paper we have discussed the role of three iconic characters: the emblematic Hello Kitty, Kumamon, the lovely bear created by the government of Kumamoto Prefecture (fapan) and Gudetama, a lazy egg yolk produced by the Japanese company Sanrio in 2014. The selected characters reflect different types and personalities and each of them serves a specific purpose, but via the analysis conveyed we conclude that perhaps their main aim is to persuade and create a long-term relationship with the public.
\end{abstract}

Keywords: Japanese; Kawaii; Cute; Advertising; Fictional characters. 


\section{Introduction}

This article aims to explain the meaning and role of kawaii ('cute') characters in Japanese advertising. After the end of WW2 Japan went through a period of great difficulty which did not affect only the society's structure, but also people's lives (Dower, 2000, 36-37). The young Japanese surrounded themselves with cute (kawaii) objects in order to erase or to blur the wartime period and to rebel against traditional Japanese culture (Kinsella, 1995, 224). This choice can be perceived as a form of distraction from reality. The new generation of anime (Japanese animation) and manga (Japanese comics) creators were inspired by Western culture and in consequence their work denoted a sweeter (kawaii) style. As Kinsella $(1995,220)$ notes, „kawaii style dominated Japanese popular culture in the 1980s.” $(1995,220)$. Even though this phenomenon was neglected for a long time by scholars because it was considered inferior to Japanese traditional arts and culture, from 2010 onwards many studies on the concept of "cute" in general started to appear. "Cute studies", a new field proposed by Prof. Joshua Paul Dale, specialized in cultural, performance and gender studies are flourishing, and the number of scholars interested in this topic is increasing, proof being the first collective volume on this "powerful affective register" (Dale et al., 2016, 1) published in 2016. Through this article we intend to contribute to the development and understanding of this concept and to reveal a part of the Japanese worldview as seen through kawaii characters used in adverts. "Cuteness" is an important feature of contemporary Japanese culture and the popularity and rapid spread of kawaii goods and characters indicates a worldwide tendency to "adopt" kawaii things as a means of dealing with anxiety and alienation (Murakami, 2005, 141). We believe that the study of Japanese kawaii culture and its forms is important not only for the development of Japanese studies, but also for increasing multicultural understanding. To our knowledge, this is the first attempt in the Romanian research community to gather information, correlate previous studies on the subject and try to explain the "hidden" meaning of these apparent meaningless, childish characters. In our use of the term "culture", we refer to the common values of the Japanese people, and implicitly, to the worldview. In order to differentiate between societies, Hofstede $(2001,2003,2010)$ proposes a solution for understanding how the members of a society prioritize and act. The model proposed by this theorist was initially structured on four, currently six cultural dimensions that quantify the degree of importance given to values considered fundamental or universal in any society. These cultural patterns derived from the correlation of the estimated scores of each dimension reflect in the way individuals attribute meanings, show appreciation and motivate each other. Hofstede's theory of cultural dimensions has been used in many advertising studies (see Dow, 2005; Calantone et al., 2006; Wong \& Merrilees, 2007; Okazaki, 2013) which emphasize on the importance of cultural differences because, in the end, these differences determine any buying decisions and consumer behavior. 
Following the ideas presented above, this paper aims to describe the Japanese society according to the cultural dimensions in order to find the dominant values which contributed to the appearance and popularity of cute (kawaii) characters in Japanese advertising. Advertising presents in a symbolic manner beauty ideals, shows people's priorities, way of life and customs within a given time; in other words, it reflects society's tendencies. The visual or linguistic signs used in any ad are understood and interpreted by the viewer according to his/her culture. Nonetheless, in this context the idea of "culture" can be extended to include a specific family's culture or even that of an individual (Lorusso, 2015, 12), but in this case we will refer in general terms, to "the system of common and implicit beliefs, that, somehow, have a social circulation and therefore a manifestation" (Lorusso, 2015, 12).

Considering the time-space constraint that seems to be the major problem of any advertiser, it is only natural that the visual and/or linguistic signs used in an ad are chosen with a specific purpose in mind. The (visual, linguistic, etc.) stimuli provided by the advertiser determines the way the ad is interpreted and guide the receiver to the conclusion anticipated by the advertiser (Tanaka, 2001, 16). By stimuli (or stimulus) we understand any sign used to provoke a response or cause any kind of reaction from the viewer. In the case of Japanese advertising, we noticed that from the late $20^{\text {th }}$ century, kawaii stimuli are prevalent in both commercial and non-commercial, educational advertising. One reason for this may be the Japanese tendency to use vague, indirect expressions in order to avoid direct confrontations with others and maintain group harmony (the Japanese concept of " $w a$ "). We argue that this particularity is strongly connected to the collectivistic nature of the society, which has its roots in the Buddhist and Shintō beliefs.

Consequently, we formulate the following research questions: "How" are these kawaii mascots and characters used in ads and social media advertising campaigns and how they fit the cultural specifics Even though it may seem that these characters have nothing in common with traditional Japanese culture, they are often compared to Shintō deities (Altt \& Yoda, 2007, 12) because of the enormous number of followers and communities many of them have. Another argument proving the importance of cute, adorable mascots in the Japanese society is the annual Yuru Kyara Grand Prix, an event gathering people all over Japan to decide the most popular mascot of the season. The selection criteria include: 1) the capacity to express love for a region of Japan, 2) to have a (fictional) biography and an out-of-the-ordinary (unique) behavior, 3) to make funny gestures, have an odd way of walking, acting goofy, etc. and last, but not least, to leave the impression that they are relaxed, carefree (yurui). ${ }^{1}$

In the following sections we intend to explain this phenomenon through examples from both types of advertising, commercial and educational.

1 https://www.yurugp.jp/jp/ 


\section{Theoretical framework}

In order to answer our research question, we will use Hofstede's cultural dimensions theory and we will start by explaining each of the six dimensions proposed. The scale used ranges from 0-100 (low-high), that is, the higher the score, the more intense that trait is.

Power distance refers to the way the members of a society deal with inequality, or more precisely, how individuals manage and view inequalities (Hofstede, 2003, 29). In a high power distance society each member knows and accepts its role, special respect is given to the elderly (the idea that wisdom is directly proportional to age is fundamental), and the authority of those in power is not undermined. In addition, the degree of interdependence between members is very high (parent-child, teacher-student, young-elderly).

Individualism vs. collectivism dimension "measures" the extent to which a culture encourages the independence and freedom of the individual and the degree of cohesion of the group. In highly individualistic societies, individuals tend to care only about their own well-being and that of their immediate family and feel the need for privacy. Moreover, in collectivist cultures, information circulates even more quickly among members and the message does not need to be explicit (Mooij, 2004, 183). In collectivist societies, communication style is rather indirect and probability adverbs ("probable", "possible", "perhaps", "might", etc.) are often used, while in individualistic ones expressions and adverbs that convey certainty are more used ("certainly", "undoubtedly", "without doubt", etc.).

The third dimension, masculinity vs. femininity checks which of the so-called "masculine" (possession, competitiveness, challenge, etc.) or "feminine" (cooperation, modesty, etc.) values predominate in a society (Hofstede et al., 2010, 140). In "masculine" societies, individuals love to compete and hope for financial success, while in "feminine" ones, the quality of life, safety and comfort are more important. In masculine societies, gender roles are well defined, while in feminine societies often overlap.

The dimension uncertainty avoidance has to do with how members of a society approach unpredictable situations and the level of anxiety felt. In societies where there is a constant concern to eliminate any potential threat or avoid being caught in unknown situations, clear rules, rituals and formalities are needed to organize the lives of individuals (Mooij, 2004, 184). Society members tend to trust experts and competent authorities, rather than ordinary people.

Long/short term orientation dimension shows the degree to which people are willing to let go of the past and embrace change and adapt, as well as the degree of perseverance and restraint. This index refers to some extent to the conflict between "virtue" and "truth," that is, between the ethical system proposed by Confucianism, which predominates in most Asian societies, and the Truth as value in Western 
ones, resulted from the well-known axiom "if A is true, then B (which is the opposite of A) is not true" (Hofstede et al., 2010, 249).

The last dimension, indulgence vs. restraint, added to the model in 2010, classifies societies according to the degree of "freedom" of its members, more precisely it has to do with the extent to which individuals value spending time with friends, building and strengthening social relationships, fulfilling their desires and if they feel in control of their own destiny (Hofstede et al., 2010, 281).

Cultural differences reflect in the expectations, needs and emotions of "symbol consumers" and can be explained through these cultural dimensions. By applying these ideas to the analysis of advertisements we can state that all linguistic and visual signs used reflect cultural values and show how individuals perceive reality (Mooij, 2004, 179). In other words, through ads we can understand how members of a society prioritize and how they communicate (implicitly / explicitly) at a given time or over a certain period of time. In the following part of the article we will develop this discussion and focus on the particularities of the Japanese culture based on this model.

\section{Japan's cultural profile according \\ to Hofstede's cultural dimension model}

According to Hofstede's study (2003) and the data provided via the six cultural dimensions of the model, the Japanese society, with a score of 54/100, is moderate in terms of power distance, moderately collectivistic (46/100), the most "masculine" (95/100), has long-term orientation (88/100), its members try hard to avoid uncertainties (92/100) and generally tend to control their desires and impulses (42/100).

Japan, with an intermediate score of 54/100 (Hofstede, 2003, 87), is considered a borderline hierarchical society, even though stereotypes promote the idea that it is an extremely hierarchical one, mainly because of the Japanese business environment. The attitude of the Japanese towards control, obedience and social inequality is moderate and reflects in the family, organizational and hierarchical structure (Rice, 2004, 65-66). By extrapolation, the importance of respecting societal hierarchical order reflects in language and behavior, as well as in customs and traditions (highly ritualized) (Snow, 2016, 327). Starting from these characteristics we argue that this tendency can also be seen in language, more precise in the tripartite system used by the Japanese to express different degrees of politeness: honorific, "neutral" and humble, plus the various masculine and feminine variants of common words through which the positions of the interlocutors are clearly defined on criteria of age, social status and gender even within the family.

On this dimension, Japan scores $46 / 100$, demonstrating that it is not as collectivistic as we may think (Hofstede, 2003, 215). According to this score, Japan is less collectivistic than other Asian countries, but much more collectivistic than Western 
ones. By correlating the above scores and by considering the context-sensitive nature of the Japanese, it becomes clearer why there is a tendency to communicate in an indirect and ambiguous manner. Strong concern for the well-being of the family/group, acts of rebellion not being tolerated, but on the contrary, automatically leading to the "outlaw's" social exclusion (Hofstede et al., 2010, 329) are just a few examples in this sense. Moreover, in Japanese personal pronouns are often omitted because they are inferred (pro-drop language) and this particularity indicates, in fact, group cohesion and that members do not feel the need to define themselves by differentiation. In collectivist societies, members perceive and act in terms of "us" and "the rest", therefore the presence of an "almighty figure" seems to be necessary to ensure group harmony. For instance, the Emperor (tennō), considered the descendant of the Sun Goddess, Amaterasu, although having just a symbolic role, he represents moral and ethical order and is a reminder of "the uniqueness" of the Japanese nation.

According to the cultural dimensions proposed by Hofstede, Japan is one of the most "masculine" societies in the world (95/100). The masculine/feminine dichotomy is defined based on gender roles: "masculinity" presupposes assertiveness, toughness and the desire to achieve material success, whilst "femininity" is associated with modesty, tenderness and efforts to assure the quality of life (Hofstede et al., 2010, 186). Male values are predominant in Japanese society, mostly because of the collective aspirations, competitiveness and teamwork of the members. The dominant masculine values alongwith moderate collectivism led to the exacerbation of competition in Japan, but at a group level, not individual. Moreover, via the sum of the scores estimated for these two dimensions we can understand the high level of rigor in the society, the pattern of submissiveness and the Japanese tendency to put above the interests of the family/group/society.

According to Hofstede et al. $(2010,92)$, these peculiarities can be seen in Japanese advertisements as well, in which signs and symbols that suggest peace and comfort are often used. We argue that the use of kawaii mascots and affect words contributes greatly to this peaceful atmosphere. Moreover, in collectivist societies confrontations are avoided at all costs, therefore negations are avoided (Hofstede et al., 2010, 106-107). The Japanese prefer to use ambiguous words and expressions such as "deshö" ('probably'), "darö" ('probably'), "kamoshiremasen" ('possibly') because in this way disapprovals are only suggested, not made explicit.

Confucian philosophy also contributed to the tendency towards abstraction. Consequently, Japanese culture was described by Seward $(1986,62)$ as "wet" because of the many expressions, proverbs, and sayings about the vital element of life, water (mizu): "Chi wa mizu yori mo koshi" ('Blood is thicker than water'), "Mizu wa hōen no utsuwa ni shitagau" ('People take on the color of their surroundings'; lit., Water conforms to both square and round vessels') and the popularity of the artistic genre ukiyo-e ('pictures of the floating world'). Water, a fundamental ele- 
ment in Japanese philosophy, represents change and adaptability and is often associated with emotions. In pop culture, the "wet eyes" of manga (Japanese comics) and anime (Japanese animations) characters can suggest strong emotions, enthusiasm and change.

Geographical location and climate can also influence people's worldviews. The "long term orientation" dimension shows that the Japanese do not like unpredictable situations and therefore try to avoid them at all costs. Japan scores 88/100 on this scale, thus this explains member's tendency to adopt and adapt quickly foreign elements to match their own culture, as well as the popularity of polytheism. Members act according to strict rules and their actions are quite easy to anticipate. The overwhelming number of rituals and ceremonies that do not undergo significant variations from one area to another, careful planning in case of emergencies, dress codes and strict etiquette are other examples which support this idea. There are also several customs and traditions that emphasize the beauty of transitory things or the ephemeral nature of life: ohanami ('cherry blossom festival'), otsukimi ('festival of the [autumn] moon'), bon odori ('commemoration of the dead') (Baten, 1995, 109).

The sixth dimension refers to the extent to which individuals are able to repress their impulses and desires. In Japan, to repress one's true feelings (honne) is common and even encouraged in early years of life (Moeran, 2011, 19).

Japanese cultural values also reflect in advertising, perceived as "ritual" (Hofstede et al., 2010, 9). Since the second half of the $20^{\text {th }}$ century, as a result of globalization and other factors, there has been a tendency towards using more neologisms (gairaigo) and Japanese pseudo-Anglicisms (wasei-eigo) to suggest novelty and exclusivity. Kawaii ('cute') characters and positive terms, feeling words started to be used to reduce members' feelings of isolation or alienation.

Hofstede's cultural dimensions enables understanding of the lexical choices, verbal/visual representations and possibly predict trends in advertising. Starting from the estimated scores, we can show how these values reflect in ads, identify recurring elements and explain the role of kawaii characters and mascots. One's culture influences greatly how the message is interpreted, but, despite all cultural differences, people's reactions are based on instincts. In Japanese advertisements, the usefulness of a product/service or the importance of an idea is often associated with a positive emotion, carefree state, communicated vaguely, but powerful, whilst in Chinese ones the important aspect is the object's utility and American advertising is mainly based on comparisons (Chelcea, 2016, 80).

\section{Methodology}

This qualitative content analysis focuses on the role of kawaii (,cute') characters in Japanese advertising. Even though since 2010 the number of studies on "cuteness" and the concept of "need-love" (amae) have increased, few really focus on 
the particular role of the Japanese concept. Among these we mention Koga (2009), Kawaii no teikoku (The Empire of Kawaii); Sato (2009), From Hello Kitty to Cod Roe Kewpie. A Postwar Cultural History of Cuteness in Japan; Botz-Bornstein (2011), The Cool-Kawaii: Afro-fapanese Aesthetics and New World Modernity; Yano (2013), Pink Globalization, Okazaki \& Johnson (2013), Kawaii!: Japan's Culture of Cute Pink Globalization; Dale (2016), Cute studies: An emerging field; Gn (2016), A lovable metaphor: On the affect, language and design of cute; Laohakangvalvit et al. (2019), Kawaii Engineering. Measurements, Evaluations, and Applications of Attractiveness.

Unlike its American counterpart, "cute", kawaii means much more than expressing positive feelings and making children feel safe and happy. As stated in the introduction, we are interested in finding out how are these kawaii characters and mascots used in ads and how they fit the cultural specifics. The first step in answering this question is to use the data offered by Hofstede's national cultural dimensions to try to explain the reasons behind the popularity of these cute characters. The observations regarding Japan's peculiarities made via the six indicators may explain these symbolic figure's bizarre appearance, behavior and also their importance for the Japanese society. In this high-context culture in which members hesitate to address issues or express their feelings directly, ambiguous, vague (visual/linguistic) expressions are preferred. Moreover, since cute characters seem to be indispensable in Japanese adverts and used even in governmental campaigns and initiatives, we intend to find the reason behind this apparent meaningless choice. For this purpose, we will apply Hofstede's cultural dimensions theory explained above. This method is widely used in marketing studies because it offers the possibility to understand differences in advertising practices and anticipate consumer's response to different (verbal/visual) stimulus. Each dimension aims to explain to what extent (0-100) a culture displays a certain characteristic.

After briefly explaining the fundamental principles of Hofstede's model, we focused on interpreting the indicators in order to pull together a "descriptive profile" for Japanese culture.

Our aim is to show how these fictional characters fit in the cultural specifics of Japan and try to explain the reasons behind their success both locally and overseas. For this purpose we have selected three kawaii (,cute') Japanese fictional characters frequently used in both commercial and educational advertising campaigns. For the case study we chose to discuss the role of Hello Kitty, the global figure responsible for spreading kawaii culture overseas and two other characters very popular in Japan, but perhaps not that known abroad. The second one is the mascot of Kumamoto city, Japan, Kumamon, a cute bear with rosy cheeks, innocent-looking, most of the time acting goofy. Lastly, we have discussed the symbolism of Gudetama, a depressed egg yolk created in 2014 by Sanrio Co., the same company that created the famous feline (according to Sanrio representatives, it is not a cat, but a little girl living in London). We chose to analyze these particular characters 
considering several factors: 1. diversity (character's looks, body language and mission); 2. character's popularity (Minowa, 2014, 98) and 3. (copyright) ownership (both private and public sector).

The proposed case study is part of our $\mathrm{PhD}$ research, through which we intend to explain the development, importance and usage of kawaii personae in Japanese advertising based on a corpus of almost 200 ads featuring a variety of mascot-characters, both from the private and public sector. As stated above, in this qualitative case study we are going to try to explain how these three iconic Japanese characters fit into Japanese culture specifics and for doing this, we will rely on Japan's descriptive profile resulted from Hofstede's cultural dimensions model. We will start by describing the visual characteristics of each character (appearance, particularities, gestures, etc.) and then we will try to explain what these particularities express, more precisely how are they understood in Japanese culture, so as to answer our main research question. In order to address the latter, we will analyze the words used by the characters on different occasions and in different situations (fundraising events, awareness campaigns, encouraging social participation or even promote a laidback, relaxed, playful lifestyle) and also discuss the character's fictive biography through which the audience becomes more familiar with the character. The sample selection consisted of three steps: firstly, we divided the adverts into 2 categories, commercial and non-commercial (educative), secondly, we selected rather new ads (from the last 5 years or so) in order to see how some important events, rather fresh in our minds, were/are presented in Japan and thirdly, we tried to discuss the use of these 3 iconic characters in a variety of situations, in order to analyze the phenomenon from a wider perspective.

The examples discussed here have been collected from the official website of the mascots and also from social media platforms (Facebook, Twitter) and Google search engine. The reason we selected examples found exclusively online is because they can be easily verified and further discussed by other researchers in the domain and we consider that (active) social media accounts are a quick way for keeping upto-date with all ongoing or future projects of these kawaii characters.

\section{Case study}

The dominant values in a society determine how members approach situations and prioritize things (Hofstede et al., 2010, 174). Cultural sensitivity is exploited in advertisements with the help of visual metaphors (e.g. chrysanthemum-symbol of Japan's Imperial House, the cherry blossom-symbol of the ephemeral transience of life, etc.). Following this idea, we will discuss and analyze the role of three emblematic kawaii characters, used either in commercial or educative adverts for specific purposes. 


\section{Hello Kitty-conventional "cuteness"}

After a so-called "green globalization" for which Godzilla, the Saurian monster was responsible (Tsutsui \& Ito, 2006), a second stage followed, but a more "harmless" one, full of color and entertainment. Hello Kitty (Illustration 1), a character created by the Japanese company Sanrio in 1974 (Yano, 2013, 9) following the extraordinary popularity of kawaii goods and "cute" writing style among young people, not only brought Japanese pop culture into the global spotlight, but also (indirectly) suggested a change in people's lifestyles.

Kawaii characters are like a white canvas offering the viewer the possibility to "paint" his/her own emotions. This strategy was also used when creating Hello Kitty, who although illustrated without a mouth and practically does not express any emotion, has the power to influence the mood of people around the globe. Each character (kyara) has a biography so that the audience can relate and identify more easily with it. Hello Kitty, a character looking like a cat, according to her creators is, in fact, a little girl who lives in London (Yano, 2018, 44). She gained a lot of fans worldwide due to her jovial appearance and friendly attitude. On Sanrio's official website $^{2}$ we find Hello Kitty's fictional biography: "As tall as five apples, weighting as much as three. She is a cheerful and kind little girl. She likes to make cakes and play the piano, and her dream is to become a pianist or poet. She is fluent in English and good at music. Her favorite food is her mother's apple cake. She has a twin sister, Mimi, with whom she gets along well. Birthday: October 1". ${ }^{3}$ Besides this general presentation, more specific details are provided in order to make the audience really feel part of the character's life: blood type, zodiac sign, family tree, group of friends and even owned pets (paradoxically, Hello Kitty owns a cat).

This brief description outlines the character's jovial temperament, already suggested through appearance, clothing and gestures. Through anthropomorphizing, the Japanese cat becomes an empathetic girl, a model citizen who promotes world peace. Kitty White, her full name, is instantly recognized by the bow she wears on the top right of her head, which has become one of the most recognized symbols worldwide. Although, the red bow consecrated the character, the color of this accessory represents, in fact, different moods. For example, green symbolizes desire, yellow, generosity, and purple, sweetness. On her debut she was depicted in a blue jumpsuit, wearing a red T-shirt underneath and a red bow on her right ear. The transition to "all pink" was made because it seems to be more suitable for expressing vulnerability (Nemitz, 2006, 26), thus this color helps to attract viewer's at-

2 https://www.sanrio.eu/characters/hello-kitty/

3 „Shinchō wa ringo 5 ko bun. Taichō wa ringo 3 ko bun. Akarukute, yasashii onna no ko. Kukkī o tsukuttari, piano o hiku no ga suki de, yume wa pianisuto ka, shijin ni naru koto. Ongaku to eigo ga tokui. Sukina tabemono wa, mama ga tsukutta appuru pai. Futago no ane, Mimi to wa dai no nakayoshi. Tanjōbi: 11 gatsu tsuitachi." 


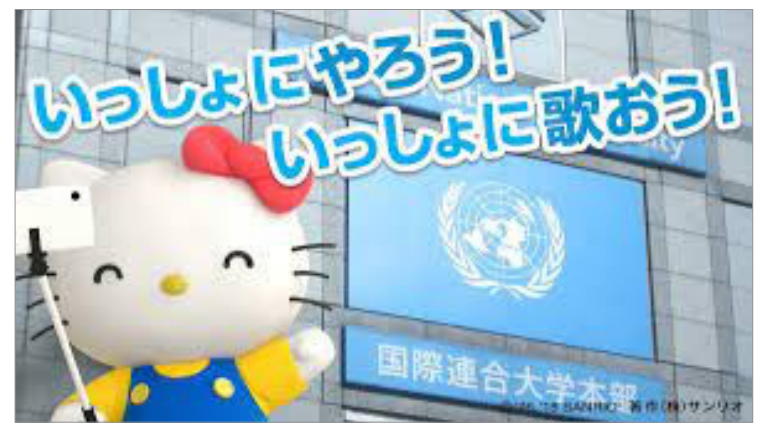

Illustration 1. Hello Kitty, UN campaign, 2018

Source: https://twitter.com/ungeneva/status/1069095565357658113

tention and gain sympathy. Associated with shame, shyness and innocence, pink suggests the transparency, sincerity and need for attention of the character. These basic emotions and feelings (curiosity, need for attention, empathy, etc.) projected in the character depend on the viewer, that is, the goal is to build an interdependent relationship between the audience and kyara ('character'). Simply put, if one feels sad then the personae feels the same. This idea is related to the principle of collectivism, specific to Asian countries. Hello Kitty, through her childish allure and the vulnerability she expresses, gained an unexpectedly large audience, being involved in various projects worldwide.

The role of Hello Kitty in promoting Japanese culture overseas is incontestable. The cute character was appointed as cultural ambassador for the 2015 World's Fair held in Milan ${ }^{4}$. The nomination of Hello Kitty attests the government's official recognition of kawaii culture and the huge potential it has in promoting Japanese culture worldwide. This episode also indicates government's intention to promote cultural education through entertainment (edutainment).

The image of Kitty-chan (chan = feminine suffix, term of endearment) is used in many adverts, humanitarian and governmental campaigns around the world (see Yano, 2013). For example, in September 2019 Cogent Communications (CCOI) made a collaboration proposal to Sanrio Co., Ltd. at UN headquarters to promote sustainable development goals with the help of the beloved character. Many videos in English and Japanese were uploaded on the character's official YouTube channel, and the actions taken can be followed on social networks by searching the hashtag (\#), \#HelloGlobalGoals. The aim of this project is to highlight 6 of the 17 Sustainable Development Goals, and some of the activity plans include debates between Kitty-chan and UN leaders and attending events on this topic around the world. During the "investiture ceremony", Hello Kitty confessed that this role is "a dream

4 https:/www.kawaiigazette.com/en/japan-at-expo-2015-from-hello-kitty-to-japan-day/ 
come true". The fact that such an important role has been assigned to a kawaii character denotes the mass influence they have and the important part they have in the development of intercultural dialogue. Hello Kitty's contribution to creating a global community is also recognized by the Secretary General for Global Communication, Melissa Fleming, who states: "Hello Kitty is bringing her enormous fan base to our global efforts to educate young people, in every part of the world [...]"

To give an even more concrete example, in one of the promotional campaign ads found on HelloSDGs's official website ${ }^{5}$, Hello Kitty, with her usual sweetness, encourages engagement and participation while taking a selfie in front of United Nations University: "Issho ni yarō!" ('Let's do it together!'), says the cute feline. Even though the character doesn't have a mouth per se, her pitchy voice and sweet-talk is a common strategy for drawing attention and stir the viewer's curiosity. ${ }^{6}$ Needless to say, the very association of this cute character with a highly prestigious organization such as the UN, commonly perceived as overly serious and formal, stirs curiosity and (perhaps) softens the overall image held about the organization by the viewer. Moreover, in Japanese, the volitional verb form is mainly used to indicate an active effort to achieve some goal and it is commonly used in this type of (social, educative) campaigns because it suggests the idea of "shared values" (Barke, 2018, 138). This is not a mere linguistic choice, but a reflection of culture and worldview, because it practically indicates what is socially acceptable and common; in this case, it is a clear indicator of the Japanese tendency to work together for a common goal (collectivism) and that the self cannot be drastically separated from the group or the community (Hasegawa, 2006, 223).

Another example is a Facebook post from UNDP Tokyo (United Nations Population Fund, Tokyo), posted on $28^{\text {th }}$ January $2020^{7}$, focusing on the $3^{\text {rd }}$ SSD goal (Health and Welfare for all). In the image we can see Hello Kitty looking at her phone while having tears in her eyes. The text gives us a hint about the cause of her sadness: "Sekaijū no ninpu-san to aka-chan o tasuketai" ('I want to help pregnant women and children around the world!'). The explicit use of "I" ("watashi"), necessary when translating the text in English, is not expressed in Japanese, thus this example also shows that the Japanese tend to have a collectivistic orientation and worldview. Moreover, the morpheme "tai" ('want to ') in "tasuketai" ('want to help') suggests the character's strong desire to make a change (Kuroda, 1992, 278), but this form indirectly implicates the audience as well, who is moved by the kawaii character's sadness and desire to help.

The last example proposed for discussion is a Hello Kitty promotional ad for Sanrio's Hello Kitty limited edition product design exhibition in Hiroshima. The

5 The official Hello Kitty-UN collaboration website: https://www.hellosdgs.com/

6 HelloSDGs campaign videos can be watched on the official YouTube channel: https://www. youtube.com/watch?v=q4G9xK9IKas.

7 https://www.facebook.com/UndpTokyo/posts/2881175051941782/ 
event aims to celebrate 45 years since the character's "birth" ${ }^{8}$ In the printed ad we can see Hello Kitty, wearing flower-shaped glasses and her iconic red ribbon on the right ear. On the right side of the ad, on a very colorful background, we find information regarding the time, place and period of the event, whilst on the left side, the lovely cat is inviting us to participate: "Watashi to issho ni kawaii mono o sagashi ni $i k \vec{o}$ " (,Come with me to look for kawaii things together!'). In this case, the use of the personal pronoun "watashi", along with the adverb "issho ni" becomes an expression for accompaniment. "Issho ni" directly suggests a group activity (Field, 2010, 179) and, we noticed that this adverb is frequently used in Japanese advertising because it leaves the viewer the impression that his involvement is needed and highly valued. As in the previous examples, we notice that the cute, innocent, childish image of Hello Kitty is used together with specific words that express "togetherness" and "bonding", and vivid colors in order to catch the viewer's attention. This "sweet talk" is preferred in Japanese society, because it offers the speaker the possibility to make requests indirectly, in a more ambiguous way, which is a virtue in a culture preoccupied with maintaining group harmony (wa) (Davies, Ikeno, 2002, 16).

Through these examples we tried to show that the recipe for success (even if we refer to product ads or educational campaigns) is, in this case, the use of gender stereotypes (tenderness, naivety, vulnerability) in relation to an anthropomorphized cat. Portrayed naively, but not ignorant, weak, but at the same time powerful, this character has gained popularity and credibility worldwide. Hello Kitty, like most kawaii characters, easily approachable and friendly, proves to be an effective tool for facilitating communication between authorities and citizens because it gives the viewer the impression that the success of any plan or idea depends entirely on the viewer's implication. In the consumerist society, purchasing kawaii products, which are excessively "sweet and harmless", is equivalent to "adopting" them (Merish in Yano, 2013, 56). Hello Kitty is the most popular Japanese pop culture figure, but the success of kawaii characters does not depend solely on notoriety, but also on the ability to arouse positive emotions and feelings. The viewer is drawn into a fantastic universe, which simulates the return to childhood innocence.

\section{Kumamon-the embodiment of the rescuer}

The winner of the first edition of the "Yuru Kyara Grand Prix" mascot contest, Kumamon is the image of Kumamoto prefecture since 2010. Unlike Hello Kitty, the anthropomorphized bear, with prominent red cheeks, large eyes and a smiling face, has the role to promote regional tourism. The name Kumamon is a combination of the Chinese character「熊」 (kuma/'bear'), also used in the name of the city, and the word mon (meaning 'person' in the local dialect). According to the

8 http://hirogura.com/2019/07/04/post-40555/ 
fictional biography posted on the mascot's official page, his duties are to find surprises and happiness and to make everyone feel good: "Boku no shigoto wa, mijika ni aru sapuraizu \& happī o mitsukete, zenkoku no minna ni shittemorau koto." ('My job is to find surprises and happiness and share it with everyone in the country') (Illustration 2). Also, it seems that the character appears only in places where it can raise someone's spirit: "Dareka o happī ni shitai to iu omoi ga aru tokoro" ('(I appear) where I think I could make someone happy'). Through this autobiography, he proclaims himself the master of good mood and convinces the audience that his mere presence arouses positive feelings. Besides being a PR specialist, Kumamon is an amateur sports instructor who encourages people to do sports for a healthier life. He has his own exercise program, "Kumamon Exercise", popular among children and even company employees and housewives. Kumamon performed his healthy routine even in front of the Imperial couple. This event shows that kawaii characters, although seem superficial and childish, have a deeper meaning. They have the power to diminish social class differences and make everyone feel part of the group (collectivist view). Kumamon holds an intermediate fishing certificate and is a shogi ('Japanese chess') beginner player. His passions denote the interest in traditional sports and the desire to make others love and cherish them too.

Kumamon's mission is to promote the local goods of Kumamoto Prefecture and Kansai and Kantō regions: "Kumamoto dake de naku Kansai ya Kantō ni mo shucchō shite, Kumamoto no oishii mono ya daishizen o netsuretsu apiru chü!' ('I go on business trips not only in Kumamoto, but also in the Kansai and Kantō regions to promote local products and the beauty of nature'). Kumamoto Prefecture is known for its spectacular scenery, seafood and high-quality agricultural products and has the largest active volcano in Japan, Aso. The mascot has gradually become popular and now has fans everywhere in Japan and is known even overseas. Unlike Disney characters, whose fans are mostly children, yuru kyara ('carefree mascots') have formed strong communities with members of all ages. Kumamon has its own office where he operates as "sales and happiness manager" and he attends local and national events. His main role (although not explicit) is to give credibility to the authorities or to certify the quality of the products and services promoted. Kawaii characters are more than mere toys, they convey ideologies and promote traditional values.

Kumamon, like other yuru kyara, solves conflicts, offers relief and comfort to people, as kamisama (deities) do. He is often compared to Jizō, the most beloved bodhisattva, the protector of children and travelers. The Japanese place small figurines with O-Jizō-san in the sacred space of Buddhist temples and on the side of country roads. Same as Kumamon, through his gentle, childish appearance, evokes positive feelings and arouses compassion. When Kumamoto city suffered immeasurable human and material losses following an earthquake in 2016, members of the online community sent dozens of messages on the city's profile page to inquire 


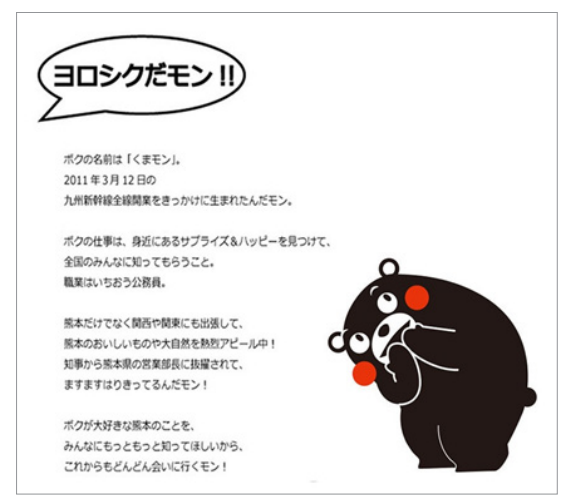

Illustration 2. Kumamon, Kumamoto city mascot, 2018.

Source: https://kumamon-official.jp/kiji0031657/index.html

about Kumamon's health. Moreover, a global prayer movement emerged, "Pray for Kumamoto" (Kumamoto, ganbare!), asking for support and assistance for the region's recovery, and Kumamon was the image of the campaign. This proves once again that the anthropomorphized bear is not a mere "cute" figure, but a symbol of hope. During those difficult times, Kumamon helped rebuilding the walls of Kumamoto Castle, led rescue operations with his head bandaged, but with the same optimism as usual. In the context of the Covid-19 pandemic, the character encouraged the citizens to obey the rules and thanked the medical staff for their effort: "Taisetsuna hito o sukuu tame isshō ken mei hataraiteiru mina san! Hontō ni hontō ni arigatō da mon!"10 ('Thank you from the bottom of my heart to all those who help us save as many human lives as possible!'). In an advert series, Kumamon is illustrated holding our planet in his arms, and saying: "Hito o omou yasashisa ga ii ashita o tsukuru!"11 ('Let's think about all the people and create a good future'). Usually, the verb "omou" ('to think, reflect, believe') is written with the Chinese character $\lceil$ 思う」, but in all Kumamon's messages this character「想う」 is used instead. Their meaning is identical, but the emotions and nuances conveyed differ. The first kanji (Chinese character) contains 「田」, which represents the shape of the brain and 「心」, the shape of the heart, which would translate as "think with the mind and feel with the heart", while the second kanji uses 「相」 (,together, reciprocally') and 「心」 ('heart'). The second one suggests a stronger emotional implication, "to imagine with your heart", "to see in the depths of your soul", etc. Using this particular kanji, the message addressed to the audience by the kawaii character is more subjective, enhances communication and leads to empathic behavior.

9 https://kumamon-official.jp/kiji0035179/index.html 10 https://kumamon-official.jp/kiji0035179/index.html 11 https://mainichi.jp/articles/20200604/ddl/k43/040/435000c 
In another ad posted in October 2020 on the mascot's official page, Kumamon presents us three essential steps for preventing the infection with the new coronavirus: "Te o arau mon/\#WashHands; Kuttsukanai mon/\#KeepDistance, Kanki o suru, \#OpenWindow". In the upper part of the illustration, the cute bear with red cheeks, looking sweet and loveable as always, wears a mask and gives us the thumbs up, suggesting that everything will be all right. In a dialogue balloon placed right next to the character, Kumamon seems to share his thoughts with us: "Kumamon to issho ni atarashii seikatsu sutairu o!" (,Start with me a new lifestyle!'). As explained in the Hello Kitty ads, the adverb "issho ni" (,together with ') is essential for establishing a connection with the audience. In this case, Kumamon refers to himself by name, not by using the personal pronoun "me", and by doing this, the overall message sounds childish, cutesy (Edwardes, 2019, 125). In Japan, it is more efficient to use cute characters, mascots or any other fictional entity when addressing the public, because they make the authorities seem more "approachable and less threatening" (Avella, 2004, 210). The same principle is used by corporations to promote their goods and services.

Kumamon is so special in Japan that he even met Empress Michiko in 2013, at Her Royal Highness's request. ${ }^{12}$ Moreover, the fact that Her Royal Highness asked Kumamon about his relationship status, shows that these mascots' (yuru kyara; 'carefree, relaxed characters') primary role is to make people loosen up and relax: “Kumamon-san wa o-hitori na no?" (,Are you single, Kumamon?') ${ }^{13}$ This is not just a mere encounter, but, in the same way that companies and authorities try to be more approachable with the help of cute characters, this episode indicates the Royal family's intention to appear more humane, more down-to-earth and unpretentious.

Another example showing how kawaii characters are used in Japanese advertising is a Japanese Red Cross Society ad from $2020^{14}$. In this ad, Kumamon plays a central role, being presented as the "ambassador" of the society. While holding in his chubby paw the symbol of the Red Cross, Kumamon draws attention to the importance of people's involvement in the development of the society and the wellbeing of others: "Ningen o sukū no wa, ningen da. Sekijūji undō ni go-kyōryoku onegai shimasu." ('The ones who save people's lives are people. Please support the Red Cross movement.') This line is also translated in English, but in this version the meaning differs to some extent: "Our World. Your move." The translated version too, emphasizes on the importance of cooperation and group work, but in the Japanese version, due to the use of the verb "onegai shimasu" (,Please'), the viewer feels like the request is made directly by the cute bear. "Onegai shimasu" (,Please'), unlike "kudasai" (,please') is used when making a politer request and, even though it does

12 https://www.bbc.com/future/article/20160719-meet-japans-kumamon-the-bear-who-earns-billions $13 \mathrm{https} / / /$ www.j-cast.com/2013/10/29187588.html?p=all

14 http://www.kumamoto-city-csw.or.jp/kumamoto-jrc/ 
not seem much, there is a subtle difference between the two forms, which makes a big difference for the Japanese listener (Miura, 1983, 154). To sum up, for this educational campaign, Kumamon plays a central role and his red chubby cheeks are perfectly matching the Red Cross symbol. Even though for an unfamiliar audience with kawaii symbolism or meaning, this association might seem odd or even inefficient, the Japanese, or even the Chinese and Koreans, have a particular fondness for everything cute, small, vulnerable or attention-seeking (Botz-Bornstein, 2007, 72)

On the official website of Kumamoto city $^{15}$ we find another interesting educational ad posted on February this year. It shows Kumamon, surrounded by four colorful beans (three green and one pink), wearing a pink scarf, smiling as always. The purpose of the ad is to help people prevent influenza. The four little beans have a meaning as well, the three green ones represent three bad habits people have when sneezing, whilst the forth, the pink one, is the "good practice" example. The text is written mainly in pink, and the whole ad is an explosion of cheerful colors. Kumamon's advice in this case is quite straightforward: "Minna de yobō!" ('Let's guard against it together!'). Like in the previous examples discussed, there are specific keywords which seem to appear quite often in this type of ads: "minna $d e$ " ('together'), the volitional form used when trying to make a subtle suggestion (Tawa, 2009, 71). We have already mention at the beginning of the paper that is phenomenon can be explained by the Japanese sensibility towards the other (collectivism, among others).

Although unable to speak, through his actions Kumamon encourages team spirit, provides emotional support and reinforces cultural values and fundamental principles. Used for both commercial and humanitarian purposes, the character proves to be a key element in maintaining social harmony and preserving traditional values. Due to his kawaii allure, goofy behavior and adorable face, Kumamon has surpassed his basic role of promoter of local goods and tourism, and became an indispensable tool for the development of the community and a mediator between authorities and the citizens.

\section{Gudetama-"atypical cuteness"}

The cartoonist expert Aya Kakeda, associates the popularity of kawaii characters with people's need to escape from everyday life, from this highly alienated era of consumerism. The characters have a leading role to distract the viewer from everyday worries and to offer the possibility to escape in an "alternative world" in which being different does not mean being weird or broken. Each kyara has its own personality, and both their qualities and flaws are made clear for the public. For obvious reasons, most characters behave responsibly and represent the needs

15 https://www.city.kumamoto.jp/hpkiji/pub/detail.aspx?c_id=5\&type=top\&id=7541 
of the model citizen (e.g., Hello Kitty), but there is another type of characters that encourage expressing one's true self (honne), hidden desires, weaknesses or flaws, otherwise suppressed. From this point of view, we can discuss about two major categories of characters: 1 . characters which are emotionally neutral, lack a "personal voice” (e.g., Hello Kitty doesn't display any facial expression), and 2. characters which represent common flaws that most normal individuals have and suggest modern man's anxieties.

The popularity of Gudetama, created in 2013 by the same company, Sanrio, attests that people's expectations and needs have changed. The fact that this character is an anthropomorphized egg is not a mere choice, the egg yolk being a popular ingredient in Japanese cuisine. An atypical, genderless character, who is known for his lack of motivation and defensive attitude, managed to create a strong community, reflecting the physical, mental and emotional exhaustion of an entire generation. Represented as an "outsider", social excluded, not belonging to any group, Gudetama highlights another facet of the concept of kawaii, datsuryoku or "exhaustion, weakness". Through its characteristics, the anthropomorphized egg yolk arouses the viewers' empathy, who resonates with its need for rest and sleep. The character's name comes from the word "gude", an onomatopoeia used to describe the lack of energy and thw short from of the noun "tamago", which means "egg". So, Gudetama is a lazy egg, devoid of any motivation or ambition, but this character represents, in fact, the inner conflict of modern man. As the character's creative director explains, people seem overwhelmed by everyday problems and, although they have the necessary skills, they no longer seem to have the energy to engage in other activities. If Hello Kitty embodies the characteristics of femininity and optimism, Gudetama, the egg yolk represents the particular sensibility of younger generations and expresses the need to find comfort in something in this alienated world. He is the anthropomorphic embodiment of depression, often expressing anxiety towards the future and seeking to escape social life and obligations: "Mirai ga mienai" ('I can't see the future'), "Sottoshite oite agete" ('Leave me alone!'). His dialogue partner, Nisetama-san, tries to raise his spirits: "Kyō wa ii koto mo aru kamo yo" ('Today will be a better day'), "Kyō wa gokigen da ne" ('You're in a good mood today, aren't you?!'). The embodiment of hope, Nisetama-san, which would translate as "Mr. Pseudo-egg", accompanies the apathetic egg yolk everywhere and is always at his disposal helping him, but even so Gudetama has no energy, or he cannot do the things he is supposed to.

In a 2018 promotional ad for Saint Marc café (Japan) ${ }^{16}$, Gudetama is illustrated in his usual state: laying around and looking tired. His specific laziness and tiredness is drawing sympathy and by extrapolation, it is increasing the cafe's popu-

16 https://collabo-cafe.com/events/collabo/gudetama-st-marccafe-chocochro/ 
larity, especially among youngsters. In the upper part of the ad, right above the image of Gudetama, we find the text "Korabo shitan da wa..." ('I made a collaboration...'), suggesting that this is the character's thought. Even the apparent meaningless suspension points indicate Gudetama's "enthusiasm" for the collaboration. The ending-particle " $w a$ " is used to emphasize and commonly used when describing something with astonishment (Matsumoto, 2004, 156). In this case, it may suggest that even Gudetama is surprised that he managed to establish a collaboration. Even though this might sound like an "anti-ad" campaign, in fact it is a quite efficient one, considering that the slogan of the campaign is "Sweet \& bitter style". The "bitter" style is represented faithfully by the lazy, but famous egg yolk. This ad was posted also on Tweeter, on Saint Marc's official page ${ }^{17}$ and quickly received over $16.1 \mathrm{~K}$ retweets and over 50 comments.

Another similar example is a 2018 ad campaign for McDonalds, Japan ${ }^{18}$. In the poster we can see Gudetama's face on a cup of an ice cream cup, surrounded by 8 small Gudetamas. The ad was created to celebrate the collaboration between Gudetama and the American company, to be more precise, some of the most known McDonald's products were "embellished" with Gudetama's for a limitededition series. In the chosen ad, Gudetama's face is on a cup of McFlurry ice cream. Right above, the hashtag “\#Gudetamatte nani aji?" ('How could Gudetama possibly taste?') is meant to draw attention and stir people's curiosity. Indeed, how would Gudetama, Sanrio's famous egg yolk taste like? There's no other way than buying McDonald's McFlurry and finding out for yourself, right? Even the colors of the limited-edition ice cream were changed accordingly, in yellowish and white tones, matching the egg yolk's look. This is a clear example of how kawaii characters are used in order to "seduce" the audience. We believe that this kind of collaboration would not be efficient if people would not have some sort of connection with the character beforehand. We believe that the popularity of Gudetama is strongly related to the Japanese longingness for a carefree lifestyle. According to Hofstede's data, Japan is a rigorous, highly ritualized society, thus, it is only natural for people to desire to be free even from time to time, while enjoying a limited-edition ice cream with the face of their favorite egg yolk, for example.

Gudetama's image is used on a wide range of products, appearing in a variety of illustrations in different poses, having a general state of helplessness and showing disinterest. Regardless of the form it takes (raw, boiled, mixed with other ingredients), the anthropomorphized egg does not hesitate to express his desire for

17 https://twitter.com/st_marc_cafe309/status/1025894154067476480?ref_src=twsrc\%5Etfw\%7C twcamp\%5Etweetembed\%7Ctwterm\%5E1025894154067476480\%7Ctwgr\%5E\%7Ctwcon\%5Es1_ \&ref_url=https\%3A\%2F\%2Fcollabo-cafe.com\%2Fevents\%2Fcollabo\%2Fgudetama-st-marccafechocochro\%2F

$18 \mathrm{https} / / /$ www.favy.jp/topics/21329 
self-isolation: "mō kaette mo ii?" ('Can I go home now?'), "jinsei nigai" ('bitter life'), "soto detakunai" ('I don't want to go out'), "okiagarenai" ('I can't get out of bed'), "hanashite" ('let me go!') (Illustration 3). The apathy and emptiness that the character feels is seen in his behavior and the words used, which stir compassion. Sanrio draw inspiration from the problems of the "Yutori" ('relaxed') generation, known as Generation Y in the West (Millennials), who have difficulty adapting and are hard to satisfy. Therefore, Gudetama is not a simple form of entertainment, but a way to draw attention to the problems of modern man. This character tries to reconcile conflicts between generations and aims to promote empathy. By purchasing and displaying a product with the image of the "lazy egg", people show that they identify (at least sometimes) with his problems.

Although Hello Kitty and Gudetama represent fundamentally opposite values, both offer an escape from reality and facilitate communication. The pressure and inner turmoil of modern man, a sensitive subject, becomes more approachable via this anthropomorphized egg, which due to its atypical appearance and behavior, stirs humor and empathy in the viewer.

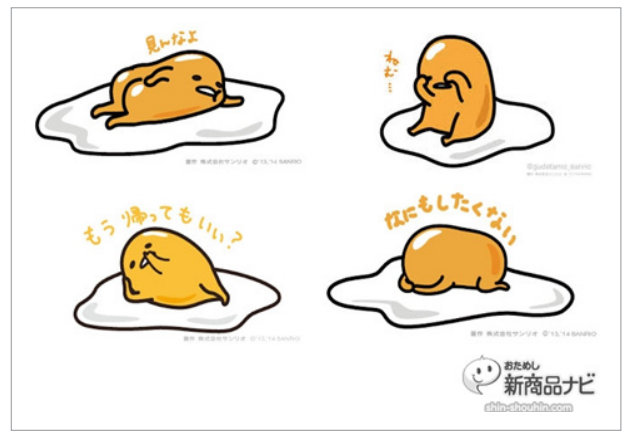

Ilustration 3: Gudetama, the lazy egg yolk, 2015.

Source: http://www.shin-shouhin.com/2015/09/08/gudetama-seven/

(c)1973 SANRIO

\section{Conclusion}

In Japan there are almost 1500 mascots, each being created with a specific purpose and mind, and each used in a specific manner, and it seems that their number is increasing (Suzuki, Kurata, 2017, 711). As we have argued in this article, kawaii has a variety of meanings and is necessary for understanding the cultural specifics and changes that have taken place in the Japanese society. From the perspective of Hofstede's cultural dimensions, we can state that kawaii characters are a product of collectivism because they encourage team spirit, promote constructive competition, helps to build trust and maintaining group harmony. Although conventionally 
in Japanese society members avoid expressing their true intentions and feelings (honne), often sharing only unanimously accepted opinions (tatemae), in Japanese advertisements are often used images and words with strong emotional charge to make the audience feel liberated from everyday stress, even for a brief moment. This utopia is constructed with the help of kawaii characters and symbols, childish terms and goofy behavior which make the viewer express his true self (jibun), but not in the Western sense of "independence", but as a form of group liberation.

Following the estimated scores provided by the cultural dimensions and the observations made by Hofstede $(2010,92)$ according to which Japanese advertisements contain mostly symbols that induce a state of peace and comfort, I present the role and functions of kawaii mascots and that of affect words. In addition, I have shown that the large number of ambiguous assumptions and expressions such as 'deshö ('probably'), 'darō' ('probably'), 'kamoshiremasen' ('possibly') used in Japanese advertising indicate that in collectivist societies direct confrontations are not accepted and the members act accordingly in order to maintain the harmony of the group. Japanese cultural values also reflect in advertising discourse, perceived as "ritual" (Hofstede et al., 2010, 9). Since the second half of the 20th century, as a result of globalization and other changes, there has been a tendency to use more and more neologisms (gairaigo), combinations of Japanese words with Anglicisms to suggest novelty and exclusivity, as well as images with kawaii characters in order diminish the feeling of alienation. In the advertising industry, efforts to eliminate risks are seen in the consistency of the actions taken and respect for tradition, both of which guarantee authenticity and quality. This case is illustrated perfectly by the policies of the companies Dentsu and Hakuhodo, which dominated the advertising market since the end of the 19th century and any other foreign companies could not implement major changes in their creative process (Tungate, 2013, 193). In this case, balance was maintained by "Japanizing" (not imitating!) foreign elements, a process that helps to avoid any aesthetic, cultural or communicative-linguistic conflict. Although conventionally the Japanese avoid expressing their true intentions and feelings (honne), often using only unanimously accepted opinions (tatemae), in Japanese advertisements are often used words and visual images with a strong emotional charge, which offer an escape from everyday life. Through the examples provided I have shown that this utopia is built with the help of kawaii characters and symbols, through childish language and behavior (reinforced on the basis of "amae" type of relationships) to release the "self" (jibun), but not in the Western sense of independence and defiance, but as a group-level freedom (see Tanaka, 2001). As in the case of other Japanese arts, advertising offers an alternative to the real world and aims to produce an emotion, an intense experience by extracting the Ego from the absurdity of life.

These scores offer an overview of the organization of societies and members' expectations, but like any study based on the (subjective) perception of individ- 
uals, the results should be regarded as general trends or predispositions, not as incontestably valid. The six dimensions, adapted to the specifics of the analysis conveyed, represent an important source for observing and understanding cultural differences.

The sum of the estimated scores of Hofstede's six dimensions model shows that the Japanese are both very keen to preserve traditional values and to adopt to new trends. The concept of kawaii is a good example in this sense, as it can easily refer to tradition and modernity likewise.

In our opinion, the analysis of advertising regarded as practice or "ritual" requires (at some point) culture-specific knowledge. The interpretation of adverts and persuasion largely depend on the degree of cultural and linguistic familiarity of the viewer.

\section{References}

1. Alt, M., Yoda, H. (2005). Hello, Please!: Very Helpful Super Kawaii Characters from Japan. San Francisco: Chronicle Books.

2. Avella, N. (2004). Graphic Japan: From Woodblock and Zen to Manga and Kawaii. Mies: RotoVision.

3. Barke, A. (2018). Constructing Identity in the Japanese Workplace Through Dialectal and Honorific Shifts. In H. Minegishi Cook, \& J. S. Shibamoto-Smith (eds.), Fapanese at Work: Politeness, Power and Personae in Fapanese Workplace Discourse (pp. 123-151). Cham: Palgrave Macmillan.

4. Baten, L. (1995). Playthings and Pastimes in fapanese Prints. Tokyo \& New York: Shufunotomo.

5. Botz-Bornstein, T. (2007). Films and Dreams: Tarkovsky, Bergman, Sokurov, Kubrick, and Wong Kar-Wai. Maryland: Lexington Books.

6. Calantone, R.J., Kim, D., Schmidt, J.B., Cavusgil, S.T. (2006). The influence of internal and external firm factors on international product adaptation strategy and export performance: A three country comparison. Fournal of Business Research, 59(2), 176-185. doi: https://doi.org/10.1016/j.jbusres.2005.05.001. .

7. Chelcea, S. (2016). Psihosociologie aplicată. Publicitatea. Iași: Polirom.

8. Dale, J. P. (2016). Cute studies: an emerging field. East Asian fournal of Popular Culture, 2(1), 5-13. doi: 10.1386/eapc.2.1.5_2.

9. Davies, R., Ikeno, O. (2002). The fapanese mind: understanding contemporary culture. Singapore: Tuttle Publishing.

10. De Mooij, M. (2004). Consumer behavior and culture: Consequences for global marketing and advertising. Thousand Oaks, CA: Sage.

11. Dow, D. (2005). Adaptation and performance in foreign markets: Evidence of systematic underadaptation. Journal of International Business Studies, 212-226. doi: 10.1057/ palgrave.jibs. 8400189 
12. Edwardes, M. P. J. (2019). The Origins of Self: An Anthropological Perspective. London: UCL Press.

13. Field, N. (2010). Narration and Revolution: An Invitation to the Writings of Kobayashi Takiji. In M. K., Bourdaghs (ed.), The Linguistic Turn in Contemporary Japanese Literary Studies: Politics, Language, Textuality (pp. 175-208). Michigan: University of Michigan.

14. Hofstede, G. (2003 [2001]). Culture's consequences: Comparing values, behaviors, institutions, and organizations across nations, $2^{\text {nd }}$ edition. California: SAGE Publications.

15. Hofstede, G., Hofstede, G. J., Minkov, M. (2010). Cultures and Organizations: Software for the Mind, $3^{\text {rd }}$ edition. New York: McGraw-Hill.

16. Kinsella, S. (1995). Cuties in Japan. In L. Skov, \& B. Moeran(eds.), Women, Media and Consumption in Fapan (pp. 220-254). London: Curzon Press.

17. Kuroda, S.Y. (1992). Japanese Syntax and Semantics: Collected Papers. Dordrecht: Kluwer Academic Publishers.

18. Lorusso, A. M. (2015). Cultural semiotics: for a cultural perspective in semiotics. New York: Palgrave Macmillan.

19. Matsumoto, I. (2004). Problems in Translating Hélène Cixous into Japanese Feminine Language. In M. Diocaretz, M. Seggara (eds.), foyful Babel: Translating Hélène Cixous (pp. 153-165). Amsterdam \& New York: Rodopi.

20. Minowa, Y. (2014). Feline fetish and marketplace animism. In S. Brown \& S. PonsonbyMcCabe (eds.), Brand Mascots: And Other Marketing Animals (pp. 91-110). New York: Routledge.

21. Miura, A. (1983). Japanese Words \& Their Uses.Tokyo: Charles E. Tuttle Company.

22. Moeran, B. (2011). Language and Popular Culture in Japan. London \& New York: Routledge.

23. Murakami, T. (2005). Little Boy: The Arts of Japan's Exploding Subculture. New Haven: Yale University Press.

24. Nemitz, B. (2006). Pink - The Exposed Color. In Nemitz, B. (ed.), Pink: The Exposed Color in Contemporary Art and Culture (pp. 26-41). Ostfildern: Hatje Cantz Verlag.

25. Okazaki, G., J. (2013). Kawaii!: Japan's Culture of Cute. London: Prestel.

26. Rice, J. (2004). Behind the Japanese Mask: How to Understand the Japanese Culture...and work successfully with it. Oxford: How to Books.

27. Seward, J. (1986). NIHONGO: A Strange and Wonderful Language. Tokyo: New Currents International.

28. Snow, N. (2016). Deconstructing Japan's PR: where is the public? In J. L'Etang, K. McKie, N. Snow, \& J. Xifra (eds.), The Routledge Handbook of Critical Public Relations (pp. 321335). London \& New York: Routledge.

29. Suzuki, S., Kurata, Y. (2017). An Analysis of Tweets by Local Mascot Characters for Regional Promotions, Called Yuru-Charas, and Their Followers in Japan. In R. Schegg \& B. Stangl (eds.), Information and Communication Technologies in Tourism (pp. 711-724). Cham: Springer.

30. Tanaka, K. (2001 [1994]). Advertising Language. A pragmatic approach to advertisements in Britain and Japan. London: Routledge. 
31. Tawa, W. (2009). Japanese Stage-Step Course: Grammar Textbook: Grammar-Reference. New York: Routledge.

32. Tsutsui, W., \& Ito, M. (2006). In Godzilla's Footsteps. Japanese pop icons on the global stage. New York: Palgrave MacMillan.

33. Tungate, M. (2013 [2007]). Adland: A Global History of Advertising. London: Kogan Page Limited.

34. Wong, H. Y., \& Merrilees B. (2007). Multiple roles for branding in international marketing. International Marketing Review, 384-408.

35. Yano, C. R. (2013). Pink Globalization: Hello Kitty's trek across the Pacific. London: Duke University Press.

36. Yano, C. R. (2018). Hello Kitty is Not a Cat?!?: Tracking Japanese Cute Culture at Home and Abroad. In A. Freedman, \& T. Slade (eds.), Introducing fapanese Popular Culture (pp. 37-46). London \& New York: Routledge.

\section{Online sources}

37. https://www.yurugp.jp/jp/

38. https://www.sanrio.eu/characters/hello-kitty/

39. https://www.kawaiigazette.com/en/japan-at-expo-2015-from-hello-kitty-to-japan-day/

40. https://www.hellosdgs.com/

41. https://www.youtube.com/watch?v=q4G9xK9IKas

42. https://www.facebook.com/UndpTokyo/posts/2881175051941782/

43. http://hirogura.com/2019/07/04/post-40555/

44. https://kumamon-official.jp/kiji0035179/index.html

45. https://kumamon-official.jp/kiji0035179/index.html

46. https://mainichi.jp/articles/20200604/ddl/k43/040/435000c

47. https://www.bbc.com/future/article/20160719-meet-japans-kumamon-the-bear-whoearns-billions

48. https://www.j-cast.com/2013/10/29187588.html?p=all

49. http://www.kumamoto-city-csw.or.jp/kumamoto-jrc/

50. https://www.city.kumamoto.jp/hpkiji/pub/detail.aspx?c_id=5\&type=top\&id=7541

51. https://collabo-cafe.com/events/collabo/gudetama-st-marccafe-chocochro/

52. https://twitter.com/st_marc_cafe309/status/1025894154067476480?ref_src=twsrc\%5Etfw \%7Ctwcamp\%5Etweetembed\%7Ctwterm\%5E1025894154067476480\%7Ctwgr\%5E\%7Ctwc on\%5Es1_\&ref_url=https\%3A\%2F\%2Fcollabo-cafe.com\%2Fevents\%2Fcollabo\%2Fgudeta ma-st-marccafe-chocochro\% $2 \mathrm{~F}$

53. https://www.favy.jp/topics/21329 